\title{
Giant Fibrovascular Esophageal Polyp
}

National Cancer Institute

\section{Source}

National Cancer Institute. Giant Fibrovascular Esophageal Polyp. NCI Thesaurus. Code C5699.

A benign, elongated intraluminal polypoid neoplasm of the esophagus. It is characterized by the presence of adipose tissue lobules separated by dense fibrous tissue bands and dilated blood vessels. The polyp is covered by normal squamous epithelium. 